\title{
O SENTIDO DA METAMORFOSE: PRECARIEDADE E PERMANÊNCIA EM MACUNAÍMA
}

Ettore Finazzi-Agrò Università di Roma "La Sapienza"- Itália Tradufão de Maria Eneida Victor Farias UFMG

Encontra-se uma extravagante notação na obraprima de Mário de Andrade - texto extravagante mais do que qualquer outro e, na acepção plena de escrita excessiva, transbordante, fora dos esquemas habituais do romance, excêntrico em relação a toda definição linear, intencionalmente transgressivo a qualquer gramática da representação.

Macunaíma, logo que chega pela primeira vez a São Paulo, atravessa, com os irmãos, um subúrbio industrial, uma floresta de chaminés que, a seus 
olhos, se torna "um cerrado cheio de inajás ouricuris ubussus bacabas mucajás miritis tucumãs". ${ }^{1}$ Portanto, essa estranha floresta fumegante fere a vista e a imaginação do peregrino, filho da mata virgem, que reduz sem angústias o estranho ao já visto, o inquietante novo à paisagem habitual da selva, $O$ que o deixa estupefato e encantado é, mais especificamente, a brancura das mulheres da cidade, com as quais ele se confronta na sua obstinada procura de "Ci Mãe-do-mato", esposa sempre pranteada "porque a rede feiticeira que ela armara pros brinquedos, fora tecida com os próprios cabelos dela e isso torna a tecedeira inesquecivel" $^{2}{ }^{2}$ Perdido no seu desejo de amor, o herói decide escolher três "cunhãs da mandioca", três moças brancas, para "brincar" com elas "na rede estranha plantada no chão, numa maloca mais alta que a Paranaguara". Depois do amor, "por causa daquela rede ser dura", Macunaíma dorme "atravessado sobre os corpos das cunhãs". ${ }^{3}$

Por ora, é bastante improdutivo, e mesmo inoportuno, perguntar-se por que Mário de Andrade introduziu no texto tantas notações desnecessárias $\mathrm{e}$ particularidades bizarras, miriades de detalhes incongruentes que constelam o romance. A sua razão de ser está talvez no próprio fato de existir, ou ainda mais no ser - textualmente - com, no justificar-se mútuo fora de (e freqüentemente contra) todo nexo causal, todo critério de realidade ou de verossimilhança. Uma das características primárias do mito é, com efeito, a autolegitimação, e Macunaíma possui, como foi notado muitas vezes, todas as propriedades do relato mítico.

Apesar disso, coloquemo-nos a pergunta e arrisquemos algumas respostas. Por que, então, permanece no texto o indício, aparentemente inútil, do dormir atravessado de Macunaíma sobre os corpos das três prostitutas (já que esta é a profissão das três moças)? Indicação supérflua, repito, como tantas outras no romance, motivada, no caso, somente pela dureza da cama, apresentada como uma rede de tipo particular, plantada no chão

1. ANDRADE, 1985. p.31.

2. Ibidem.

3. Ibidem. e não suspensa.

Podemos talvez começar a responder justamente desse ponto: tornando visível uma oposição semiológica entre rede e cama, na qual está subentendida toda uma série de suboposições carregadas de um evidente valor metafórico (leveza $\mathrm{x}$ peso, macio x duro, suspenso x não-suspenso -- e isto mesmo se o fato de encontrar-se em um plano alto estabelece interseção de tal antinomia com a imagem da verticalidade urbana em oposição à horizontalidade da dimensão da selva). Mas a contraposição é também, e sobretudo, contraposição cultural entre indígena e não-indigena, e subordinação ambiental entre mata e cidade: o herói, em suma, logo que chega a São Paulo, parece lembrar saudoso o modo de dormir da sua gente.

$\mathrm{Na}$ realidade, a saudade da rede não diz respeito tanto ao sono, quanto à sua identificação com a esposa morta, a recordação dos abraços que ela soubera dar-lhe na rede tecida com os seus longos cabelos. Portanto, a equivalência é entre a mulher, que enredou em sentido pleno o protagonista, e a rede, que atua como contraponto da conexão entre o leito e as três filhas da mandioca. O que ressalta, inevitavelmente, um aspecto subentendido da oposição entre os dois leitos: a rede é reservada a uma relação a dois, a cama parece disponível à promiscuidade, à relação plurinominal.

A iniciação de Macunaíma no universo urbano, a sua compreensão do novo, passa, pois, por um aprendizado de ordem sexual, através de uma aproximação erótica que o faz conhecer, pode-se dizer que graças à cama, o caráter marcante da cidade: a sua dimensão plural, domínio da multidão, da massa sem nome - como sem nome permanecem, com efeito, as três prostitutas. Espaço promíscuo, em última análise, no qual convive fisicamente uma pluralidade de corpos, um conjunto heterogêneo de rostos, de objetos, de imagens.

Não se pode esquecer, em tal perspectiva, como a sexualidade representa para Macunaíma uma forma capital (poder-se-ia mesmo dizer bíblica) de "conhecimento", se é verdade que a sua primeira relação sexual ele a teve aos seis anos de idade 
com Sofará, companheira do irmão mais velho Jiguê, ${ }^{4}$ confirmando, assim, como mesmo a sua iniciação no mundo indígena, no universo da mata, tenha já assumido inevitavelmente a forma alegre da aproximação carnal, da relação erótica. $\mathrm{E}$, de resto, não poderia ser diferente para um personagem que aparece intimamente ligado à corporalidade, desde sempre preso à esfera do instinto -da necessidade, da urgência física -- até tornar-se o emblema: símbolo, ao mesmo tempo, da obtusidade do corpo e da sua astúcia suprema, ${ }^{5}$ da sua preguiça e da sua lepidez, da sua indolência e da sua afoiteza.

Não por acaso a frase "Ai que preguiça" e a pesada consciência da inanidade de cada gesto acompanham Macunaíma por todo o romance, associando-se, por outro lado, a um incansável ativismo, a um fazer frenético e insaciável. A fome, precisamente, como o sexo: manifestações primárias de um errante estar no mundo, de uma relação nunca esgotada - e por isso sempre completa, sempre bem conhecida - com as coisas, com a materialidade do existir. Já que tudo é profundamente humano, natural, "fisiológico", no mundo de Macunaíma, assim como tudo é também contemporaneamente, mítico, divino, a começar por ele mesmo: ambigüidade profunda de uma dimensão que, mesmo sendo fundamentalmente homogênea, radicalmente imutável e já conhecida (segundo as leis do mito), deve, não obstante, ser incessantemente experimentada, explorada fisicamente na sua heterogeneidade e no seu eterno, cíclico, devir.

$\mathrm{O}$ protagonista, mesmo enquanto herói de uma corporeidade que é compenetração teofânica com o real, só pode conhecer a cidade através da sua relação carnal com as brancas habitantes deste lugar pluriforme e infernal, percorrido por um "des-

4. ANDRADE, 1985. p.10-12.

5. Basta lembrar, ao lado das inumeráveis provas de safadezas do herói, pelo menos a sua incapacidade de resolver os três enigmas propostos pela jovem filha de Ceiuci: adivinhação de duplo sentido, do qual Macunaíma entende somente, dada sua mesquinhez e sua corporalidade, o lado obsceno. Cf. ANDRADE, op. cit., p.83. propósito de papões roncando, mauaris juruparis sacis e boitatás", atravessado por "grotões donde gentama saía muito branquinha branquíssima, de certo a filharada da mandioca!..."6 Experimentar esse "lugar de trevas" (paradoxalmente marcado pelo candor) significa, para Macunaíma, penetrálo fisicamente, fazer amor com ele - e o seu comportamento está em sintonia com as premissas, com um mundo totalmente regulado pela lei do desejo.

Porém, Mário de Andrade acrescenta que o herói dorme atravessado sobre os corpos da mulheres. Detalhe que marca a sua sensualidade, mais uma vez, fantasia erótica que penetra, estetizando-o, no horizonte ético do protagonista. Todavia, tal postura, este "estar atravessado", acrescenta, a meu ver, alguma outra coisa na definição do personagem e no desvelamento da sua função emblemática: diz-se que a verdade de Macunaíma é uma verdade transversal em relação à dos corpos metropolitanos.

Em outras palavras, foi-lhe atribuído o papel privilegiado de estabelecer a interseção, de cobrir transversalmente o espaço plural dos corpos brancos da cidade. E note-se, por contraste, como a sua relação com $\mathrm{Ci}$, mãe-símbolo do mato, divindade antes violada e depois fecundada em uma relação "de rede", remete a uma posse exclusiva, a um domínio mútuo, a uma "prisão" que a cama parece impedir.

Não se pode por certo afirmar que o herói andradino goze freqüentemente de relações eróticas de grupo, mas é certo que a sua sexualidade, a prescindir de $\mathrm{Ci}$ e de outro tipo de leito, é descrita como atividade frenética e episódica: desejo de uma posse momentânea que transcorre rapidamente de um objeto a outro, de um corpo a outro -- contemplando, todavia, pelo menos um outro caso notável de relação "a quatro": o que liga Ma-

\footnotetext{
6. ANDRADE, 1985, p.31: "Que mundo de bichos! Que despropósito de papões roncando, manuaris, juruparis, sacis e boitajás nos atalhos, nas socavas, nas cordas dos morros furados por grotōes donde gentama saía muito branquinha, branquíssima, de certo a filharada da mandioca!"
} 
cunaíma às três filhas de Vei, "a Sol". ${ }^{7}$ Isso vem confirmar como, mesmo fora do ambiente urbano, o estatuto do herói, que chamei a sua "verdade", depende essencialmente da capacidade de ocupar mais corpos de uma vez, ou então, de maneira complementar, de ocupar muitos deles em seqüência.

Capacidade copulatória, em conclusão, no significado originário de atividade que une, liga, junta, e que, fora da metáfora sexual, reforça como esse personagem é definido precisamente pela sua faculdade de possuir, contemporânea ou sucessivamente, várias identidades, também pela sua disponibilidade de unir, de "fazer as ligações", a mover-se dentro e através de instâncias e/ou realidades diversas.

Em outro trabalho, falei de tal função conectiva de Macunaima, cuja "ausência de caráter" (herói sem nenhum caráter nos diz o título do romance) se revela, na realidade, idoneidade a mediar entre caracteres contraditórios, a conjugar entre eles as muitas qualidades do universo racial, social, cultural brasileiro. ${ }^{8} \mathrm{~A}$ amorfia do protagonista, o seu não ser propriamente ninguém, torna-se, sob tal ótica, garantia necessária de um polimorfismo potencial, de uma adaptabilidade do personagem para desempenhar muitos papéis, para ser, no fundo, todos.

Adesão, pois, a uma realidade heterogênea, permeabilidade e ao mesmo tempo penetração: atributos primários de uma corporalidade excedente que permite - se justa a hipótese de Bachtin uma quebra das barreiras entre interior e exterior, próprio e impróprio, entre o espaço físiológico e o natural. Porque, de fato, o acesso erótico de Macunaíma ao mundo que o circunda é contrabalançado pela sua acessibilidade, pela sua abertura ao mundo exterior, num movimento ambiguo que designa, contemporaneamente, a disponibilidade para cobrir transversalmente o múltiplo e, por ou-

7. ANDRADE, 1985, p.54-55.

8. FINAZZI - AGRÓ. Il neutro e il molteplice: considerazioni sul modernismo brasiliano, publicado nos Anais do Congresso sobre Le Americhe degli anni trenta (Roma, Bulzoni). tro lado, para ser atravessado pela multiplicidade.

Não é difícil, nesse sentido, aplicar ao herói andradino as considerações aventadas por Károly Kerényi a propósito do "trickster" da mitologia Winnebago, já que também "a sua natureza, inimiga de todo limite, é aberta em todas as direções" e sendo "fálica em excesso, não sabe limitar-se a um único sexo". ${ }^{\prime}$ Basta lembrar aqui o episódio em que Macunaíma, transformado em "francesinha", tenta seduzir o gigante Piaimã para roubar-lhe o amuleto de $\mathrm{Ci} .{ }^{10}$

A referência a um conhecido estudioso do mito como Kerényi me dá oportunidade, por outro lado, de rever a aludida capacidade do nosso herói de "abolir os limites", transitando através de muitas identidades, à luz de um mitologema fundamental como é a metamorfose, interpretável também, da mesma forma que a posse erótica, como um modo para "entrar no corpo de um outro". ${ }^{11} \mathrm{O}$ universo de Macunaima resulta, com efeito, entretecido de metamorfose, assim como é entrelaçado de relações sexuais, de tal modo que a qualificação do herói aparece estreitamente vinculada não só a seus dotes corporais, mas também à sua atitude de transformar-se, além de transformar a realidade circunstante.

Que sexualidade e metamorfose devam ser entendidas como manifestaçōes complementares confirmam, de resto, os muitos casos em que elas estão associadas no romance, designando, mais uma vez, o duplo papel, ativo e passivo, do protagonista. Assim, se Macunaima pode transformar-se em "francesinha" para enfeitiçar Piaimã, por outro lado, já se transformara em "um príncipe belís-

9. RANDIN, et al. 1979. p.227.

10. ANDRADE, 1985, p.38-43. Em tal episódio, mesmo se não se assiste explicitamente a uma consumação da relação erótica entre Piaimã e Macunaíma, encontra-se, todavia, uma indiscutível metaforização, quando o herói, escondido em um formigueiro (a evidente conformação uterina) para fugir às cobiças do gigante, é atingido por uma palmeira inajá que o seu perseguidor introduz na embocadura do refúgio: "com as pernas abertas, o herói ficou, por assim dizer, estacado no alto da palmeira".

11. STAROBINSKI, 1975, p.170. 
simo" para ter a sua primeira relação sexual com Sofará. ${ }^{12}$ Em suma, parece que Mário de Andrade quis tirar proveito do ambíguo valor dessas duas forma de "posse" para conotar a ambiguiidade de um personagem chamado, por seu lado, para emblematizar a equívoca condição do homem brasileiro.

Se, de fato, se lê a metamorfose como imagem da mudança, da transformação, não se pode deixar de ver em Macunaíma o emblema, justamente, de uma total impermanência, que evoca, por sua vez, a possibilidade/capacidade do brasileiro de transitar através dos "lugares plenos" da identidade. Homem "sem", ele anula, com efeito, no curso do romance, as barreiras entre as raças (índio-negro, no início, tornar-se-á milagrosamente "branco e louro de olhos azuis"), ${ }^{13}$ ignora as fronteiras entre cidade e mata (passa entre as chaminés como em um palmeiral), anula até, como vimos, os limites sexuais entre masculino e feminino.

Se, por outro lado, vê-se na metamorfose a capacidade de reunir em um só lugar, de manter dentre os limites de uma única figura muitas imagens heterogêneas, não se pode ignorar como também nesse caso Macunaíma corresponde às esperas, cobrindo transversalmente as diversidades que marcam o universo étnico, social e cultural do Brasil. Defini "neutralização", em outro trabalho, como a função aglutinante do herói andradino, e acrescento que ela pode também ser interpretada como uma fixação, uma prisão, uma coerência de fundo que permanece através da mudança. Que se queira chamar de mestiçagem esse "lugar neutro" é, em todo caso, a dimensão na qual o polimorfismo brasileiro, simbolizado por Macunaíma, tende a descarregar as próprias tensões: espaço de compromisso, de mediação, no qual se diluem as muitas contradições que caracterizam aquela realidade ( Norte/Sul, Litoral/Interior, Patrões/Escra-

12. "Ele botou corpo num átimo e ficou um príncipe lindo. Andaram por lá muito [...] Nem bem o menino tocou no folhiço e virou num principe fogoso. Brincaram." (ANDRADE, op. cit., p. 10 e 11).

13. ANDRADE, 1985, p. 30. vos, Brancos/Negro/Índio). ${ }^{14}$

A metamorfose se presta a uma sólida metáfora de tal conciliação paradoxal entre coerểncia e mutação, entre paralisação e movimento, da qual Macunaima é a representação heróica. Sólida, reforço, na medida em que é historicamente ambígua, chamada como é a designar para sempre seja a evolução, seja a involução, seja o crescimento, seja a regressão (pense-se somente no Asno de ouro de Apuleio, em que a metamorfose eqüina de Lúcio é, sim, regressão a um estado animal, mas, ao mesmo tempo, via de acesso, de iniciação aos mistérios eleusinos), também para representar tanto a conquista, quanto a fuga (recorde-se a função especular da metamorfose nas aventuras amorosas de Zeus e nas tentativas de Proteu de frustrar os próprios perseguidores). ${ }^{15}$ Esse duplo sentido permanece, ao pé da letra, no romance andradino (Macunaíma se transforma para conquistar Sofará, enquanto Palauá, a onça pintada, torna-se "máquina-automóvel" para fugir à ira do tigre negro); ${ }^{16}$ o duplo sentido, dizia eu, permanece, remetendo, todavia, mais em profundidade, a uma ausência de sentido que é conjunção "impossivel" de dois sentidos, a uma neutralização, fruto de uma assimilação entre contrários.

Em suma, como na metamorfose de Hermafrodite, pela qual os dois se conciliam em um, não sendo uma coisa nem outra, e sendo ambas ao mesmo tempo, assim, através das transformações de Macunaíma, Mário de Andrade tenta, a meu ver, transmitir-nos a imagem de uma identidade que não é una, de uma condição histórico-cultural que não tem forma definida mas que encontra a sua especificidade dessa indefinição, que é, por sua vez, reassunção de muitas definições e de muitos específicos. O que quero dizer é que o caráter brasileiro é pensado no romance como a imagem heróica de uma falta que permanece, porém, mistura de vários caracteres. Latência, poder-se-ia

14. FINAZZI - AGRÓ, op. cit..

15. Sobre tal ambivalência da metamorfose na mitologia clássica, cf.STAROBINSKI, 1975. p.171.

16. Esta transformaçāo é descrita pelo próprio Macunaima em um conto inserido no romance, $\mathrm{cf}$. ANDRADE, 1985.p.101-103. 
também chamá-la, no sentido de um estado indiferenciado e vazio que é, na realidade, estado de plenitude potencial.

A confirmação me parece que nos possa vir justamente do trecho em que é declarada a natureza "sem caráter" de Macunaima. Ele apenas enganou pela enésima vez os irmãos Maanape e Jiguê, conseguindo ainda "rir" com uma das companheiras deste último (a bela, piolhenta, Suzi). Exasperados com o comportamento do herói, Maanape, o negro velho que "entende de magia", e Jiguê, o jovem índio "bobo mesmo", caminham um em direção ao outro no corredor; quando se encontram, "Maanape ficou zangado e foi falar com Jiguê. Mas Jiguê também já vinha pra falar com Maanape. Se encontraram no corredor. Maanape contou pra Jiguê e Jiguê contou pra Maanape. Então eles verificaram que Macunaíma era muito safado e sem caráter." 17

A ausência é aqui, como se vê, designada claramente enquanto "falta": culpa, certamente, mas também -- e contemporaneamente - estado de não-posse que resume as potencialidades do herói. ${ }^{18}$ Não é à toa que os dois irmãos de raças diferentes se encontram em um corredor: lugar físico de trânsito, de passagem, dimensão que não é cômodo, não é propriamente habitação, mas funciona como ligação entre os lugares habitáveis, coloca em ligação os cômodos, une os diversos "hábitos". Somente em um corredor, nesse sentido, poder-se-ia dar a epifania do heroísmo "neutro", sem caráter, de Macunaíma: como constatação de compromisso que deriva da relação entre opostos (o negro e o índio, o culto e o inculto, o velho e o novo). O protagonista é ausente, em falta, mas mesmo a sua falta (também em sentido éti-

17. ANDRADE, op. cit., p.98.

18. Este duplo sentido é claramente denunciado pelo próprio Mário de Andrade no segundo prefácio do romance, datado de 27 de março de 1928 e nunca publicado (o romance, de fato, saiu sem nenhum prefácio do autor). Ver em Heloísa Buarque de Hollanda, Macunaima: da literatura ao cinema, (Rio de Janeiro: José Olympio, 1978. p.39): "E resta a circunstância da falta de caráter do herói. Falta de caráter no duplo sentido de indivíduo sem caráter moral e sem característica". co) é o que faz encontrar e coincidir dois pontos de vista, duas instâncias, duas identidades entre eles contrapostas que ele sintetiza.

Não se pode, também, deixar de notar como a qualificação de "homem sem" representa a conclusão de um conto cruzado com as gestas do herói, terminando, a meu ver, por oferecer-nos uma chave de leitura do mesmo relato que se está desenvolvendo sob os nossos olhos. Se, em outros termos, a verdade de Macunaíma é desvelada por narrações que se encontram, tal verdade é também aquela em que se encontram, tal verdade é também aquela em que se identifica o romance que nos fala dele. Basta, para isso, lembrar como Mário de Andrade invoca como modelo os cantadores nordestinos: ${ }^{19}$ imagem de uma efabulação que é freqüentemente o produto precário da conjunção/contaminação de diversas fabulae; arquétipo de um epos rudimentar, em eterno devir, mas também perenemente fiel às fontes.

$O$ texto andradino pode, em tal perspectiva, ser visto como uma espécie de paradigma narrativo no qual estão também descritas, metatextualmente, as peripécias de um relato que é o resultado de mediações entre imagens heterogêneas, de um mito que é resumo de muitos mitos que o fundem, mas que ele, por outro lado, verifica penetrandoos, colocando-se atravessado sobre eles. Nesta direção, a meu ver, são interpretadas as famosas declarações de Mário de Andrade, aparentemente desconcertantes, sobre o próprio romance, enquanto resultado não de imitação, mas de cópia:

"Copiei, sim, meu querido defensor. O que me espanta e acho sublime de bondade, é os maldizentes se esquecerem de tudo quanto sabem, restringindo a minha cópia a Koch-Grünberg, ${ }^{20}$ quando

19. HOLLANDA. Macunaima: da literatura ao cinema, p.52-53.

20. A referência é ao excelente estudo do etnólogo alemão Theodor Koch-Grünberg, Vom Roraima zum Orinoco. Ergebnisse einer Reise in Nordbrasilien und Venezuela in den Jabren 1911 1913, 5 voll, Berlin-Stuttgart, 1916-1928. O modelo, todavia, deve ter sido sobretudo o segundo volume desta obra (Mythen und Legenden der Taulipang __ und Arekuna __ Indianer, $1^{\text {a }}$ ed: Berlin, D. Reimer, 1916; $2^{\mathrm{a}}$ ed.: Stuttgart, Strecker und Schröder Verlag, 1924), no qual, de fato, é narrada a lenda de Macunaima 
copiei todos [...]. Confesso que copiei, copiei às vezes textualmente." 21

Arte citacional, pois, discurso que reflete outros, pot-pourri de memórias alheias que dão vida, contudo, ao seu livre combinar-se, a um produto romanesco profundamente novo, que regenera o conhecido conferindo-lhe um sentido inédito: ${ }^{22} \mathrm{o}$ sentido de uma identidade cultural que é assim somente graças a um movimento de apropriação e de transformação incessante de várias identidades.

Portanto, se "o relato é uma grande metáfora e, logo, um processo de metamorfose", 23 como escreveu Franco Rella, Macunaima, como texto e como personagem, é justamente a postulação, no relato, de uma figura que transita através da pluralidade das imagens, penetra nos corpos textuais alheios, submetendo-se a continuas metamorfoses, mas conseguindo, justamente em virtude de tal deslocamento e de tal transformação, manter em um só lugar a pluralidade e metaforizar, através da interseção, a multiplicidade dos modelos e dos percursos culturais vigentes no Brasil.

Macunaíma, o herói de uma identidade sem identidade, de uma corporalidade insofrida dos limites, Macunaima, o mediador sem caráter que circula entre caracteres diversos, mudou-se, por todas essas propriedades que não fazem "uma" propriedade, em um mito que é a própria imagem do paradoxo brasileiro. Em um mythos, em última análise, que na sua acepção originária significa relato que fixa em uma constelação de sentido o que se dá como mutação perene, redescobrindo a possi-

e de Piaimã.

21. Citação da conhecida "carta aberta" de Mário de Andrade a Raimundo Moraes, publicada no DIÁRIO NACIONAL de São Paulo, em 20 de setembro de 1931.

22. De resto, que a atividade de construção mítica apresente, de forma genérica, notáveis afinidades com a bricolagem -recompondo em um sentido novo elementos derivados de outros conjuntos estruturais __ foi intuído por Claude Lévi-Strauss, que instituiu tal paralelismo, ilustrando-o em algumas páginas famosas do scu estudo sobre $O$ pensamento selvagem.

23. RELLA, 1986. p.10. As considerações que se seguem baseiam-se $\mathrm{cm}$ outros dois estudos de Franco Rella: Miti e figure del moderno (Parma, Pratiche, 1981) e Metamorfosi (Milano, Feltrineli, 1984). bilidade de uma permanência dentro e através da precariedade.

O herói andradino transformar-se-á, não por acaso, na sua metamorfose suprema, a Ursa Maior: e agora "banza solitário no campo vasto do céu" 24 -- numinosa ambigüidade de uma constelação errante.

\section{REFERÊNCIAS BIBLIOGRÁFICAS}

1. ANDRADE, Mário de. Macunaima, o herói sem nenhum caráter. Belo horizonte: Itatiaia, 1985.

2. FINAZZI-AGRÓ, Ettore. Il neutro e il molteplice; considerazioni sul modernismo brasiliano.

LE AMÉRICHE DEGLI ANNI TRENTA, Roma. Anais... Roma: Bulzoni.

3. HOLLANDA, Heloisa Buarque de. Macunaíma; da literatura ao cinema. Rio de Janeiro: José Olympio, 1978.

4. KOCH-GRÜNBERG, Theodor. Vom Roraimazum Orinoco; ergebnisse einer reise in Nordbrasilien und Venezuela in den jahren 1911 - 1913. Berlin: D. Reiner, 1916. 5v.

5. ______. Vom Roraima zum Orinoco; ergebnisse einer raise in Nordbrasilien und Venezuela in den jahren 1911 - 1913. 2. ed. Stuttgart: Strecker und Schröder Verlag, 1924. v. 2: Mythen und legenden der Taulipang - und are Kuna - indianer.

6. RANDIN, P., JUNG, C.G., KERÉNYL, K. Il briccone divino. Milano: Bompiani, 1979.

7. RELLA, Franco. La battaglia della verità. Milano: Feltrinelli, 1986.

8. _-_._. Miti e figure del moderno. Parma: Pratiche, 1981.

9. ____ Metamorfosi. Milano Feltrinelli, 1984.

24. ANDRADE, op. cit., p.133: "A Ursa Maior é Macunaíma. É mesmo o herói capenga que de tanto penar na terra sem saúde e com muita saúva, se aborreceu de tudo, foi-se embora e banza solitário no campo vasto do céu." 
100 ANOS DE MÁRIO

10. STAROBINSKI, J. L'occhio vivente. Torino: Einaudi,1975. p. 170.

\begin{abstract}
The carnal attitude affected by Macunaima, the "hero without any traii" of Mário de Andrade's novel (1928), allows us to reconsider this character as an emblem of body, cancelling (in accordance with Bakhtin's opinion) the barriers between "interior" and "exterior" — a body that passes across the "full places" of identity, combining manifold experiences into a substancial, ideological, uniformity. In this sense, the amorphous condition of Andrade's hero, in connection with his ability to "enter in another's body" (Starobinsky), with his metamorphosing faculty, becomes a paradigm of the Brazilian condition, which is also characterized by his tendency to identify itself in an absence, as a product of mediation between different cultural patterns. Macunaíma, as a text and as a character, is, after all, the novelization, the "metaphor" (Rella), of an identity that consists of a lack, that lasts into and across the transformation.
\end{abstract}

